\title{
House of Cards
}

By Patricia Thompson

Fall 1996 Issue of KINEMA

\section{. . . AND THEIR FESTIVALS}

House of Cards Producer, writer, director, editor: James Fry. Photography: Cezary Kolsut. Canada 1995, 11min.

A BRIGHT sunny morning on the wharf -- glistening water, birds wheeling and swooping overhead, and the mailman leisurely walking his route along the boards. An assortment of boat dwellers greet him and go about their daily routines in an atmosphere of peace and relaxation. It's all too good to be true. And it is!

This idyllic setting is not all it seems to be as a cacophony of the sounds of everyday modern living slowly to creep into these lives and frazzle their nerves. The old geezer dozing in his deck chair develops a horrendous snore; banging away with hammer and nails a distraught man makes a tiny coffin for his departed pet; there's a lot of deafening sound from hand and chainsaw and then there's the dental floss queen -- squeak squeak... Worst of all, the nervous builder of the house of cards fears vibrations and is driven to glue his masterpiece together.

This gentle little dig at the stresses and strains of our noisy life was shot silent and a created soundscape composition was added, which works quite well. It's nicely shot in the picturesque setting of Fisherman's Wharf, Victoria BC.

\section{Author Information}

Patricia THOMPSON (d. 1999) was Publisher and Editor of Film Canada Yearbook and Canadian Editor for the International Motion Picture Almanac and the International Television and Video Almanac (Quigley, NY). She was reviewing Canadian short films for several decades. 